\title{
LUGARES INVISIVEIS DO BAIRRO RESTINGA: A PARTICIPAÇÃO POLÍTICA DAS LIDE- RANÇAS COMUNITÁRIAS NO ORÇAMENTO PARTICIPATIVO DE PORTO ALEGRE
}

\author{
Helena Bonetto* \\ * Mestre e doutoranda em Geografia pela Universidade Federal do Rio Grande do Sul, Professora do sistema público de ensino do Município \\ de Porto Alegre; E-mail: helena.bonetto@yahoo.com.br.
}

Recebido em 04/2015. Aceito para publicação em 11/2015. Versão online publicada em 13/01/2016 (http://seer.ufrgs.br/paraonde)

\begin{abstract}
Resumo: 0 presente artigo é resultado da pesquisa realizada para a elaboração da dissertação de mestrado As percepções topofílicas/topofóbicas das lideranças comunitárias do bairro Restinga antes e depois da implementação do Orçamento Participativo, já concluída. 0 principal objetivo é evidenciar e compreender de que maneira a participação política e a conquista de equipamentos públicos por meio do orçamento participativo (OP) contribuíram para a construção de lugares de luta por equipamentos urbanos, no bairro Restinga, visíveis apenas para as lideranças comunitárias. 0 marco teórico desta investigação é constituído pelas obras dos autores Yi-Fu Tuan e Alicia Lindón. Os conceitos utilizados são: espaço, lugar, lugares invisíveis e parcialmente visíveis. Os procedimentos metodológicos adotados para compreender os lugares do bairro antes e depois da implementação do OP foram: revisão bibliográfica, entrevistas do tipo narrativa, levantamento das obras no website da Prefeitura de Porto Alegre e construção de bancos de dados para a composição de mapas temáticos e gráficos. Para a análise de dados relativa à transformação dos lugares foi adotado o holograma espacial, uma técnica de pesquisa qualitativa desenvolvida por Lindón para possibilitar a compreensão dos sentidos, da teia de significados e da simbolização atribuída aos lugares a partir das experiências espaciais dos sujeitos. A análise das narrativas demonstrou que os lugares da Restinga que se tornaram visíveis foram aqueles resultantes das lutas por equipamentos urbanos das lideranças comunitárias e da população que reside no bairro. São lugares repletos de significados, pois entrelaçam participação política, histórias de vida e transformações socioespaciais.
\end{abstract}

Palavras-chave: Orçamento Participativo. Lugar. Participação Política. Restinga

\section{Introdução}

A proposta deste artigo é compreender como a participação política das lideranças comunitárias do bairro Restinga - localizado no município de Porto Alegre, Rio Grande do Sul - no Orçamento Participativo (OP) permitiu a construção de lugares de luta por equipamentos urbanos para o bairro.

0 artigo faz parte de um projeto maior de pesquisa de mestrado desenvolvido entre os anos de 2011-2013 no Programa de Pós-Graduação em Geografia da Universidade Federal do Rio Grande do Sul, a qual se intitula: "As percepções topofílicas/topofóbicas das lideranças comunitárias do bairro Restinga antes e depois da implementação do OP em Porto Alegre", defendida em 2013, a qual tinha como foco compreender como a obtenção de equipamentos urbanos através da participação política no OP transforma as percepções topofílicas/topofóbicas que as lideranças possuíam e possuem do bairro Restinga.

Os procedimentos metodológicos estão divididos em dois momentos: o primeiro consiste na coleta de dados através da revisão bibliográfica, realização de entrevistas narrativas, levantamento das obras realizadas a partir do OP na website da Prefeitura de Porto
Alegre, construção de bancos de dados no programa Excel e composição de gráficos e mapas.

A análise das narrativas foi realizada a partir da construção de um holograma espacial. Essa técnica, para Lindón (2007a), analisa os dados coletados através da produção das narrativas e permite a compreensão dos diferentes papéis exercidos pelos sujeitos na construção social dos lugares concretos da cidade.

Os principais aportes teóricos utilizados neste artigo relacionam-se aos estudos da Geografia Humanística, assim como a concepção de lugar utilizada nesta pesquisa. Para Geografia Humanística, segundo Holzer (1999):

O lugar se comporta como um nó funcional, para o humanista ele significa um conjunto complexo e simbólico, que pode ser analisado a partir da experiência pessoal de cada um - a partir da orientação e estruturação do espaço, ou da experiência grupal (intersubjetiva) de espaço (HOLZER, 1999, p.71).

Além disso, esta investigação está centrada nas pesquisas de Yi-Fu Tuan e Alicia Lindón, os quais foram sensíveis à percepção do espaço enquanto lugar, per- 
meado de significados e símbolos. Os autores fizeram importantes reflexões sobre o desvelamento da realidade a partir do campo simbólico, e não apenas do material.

O lugar é um espaço estruturado (TUAN, 2011, p.8). Os conceitos de espaço e de lugar encontram-se definidos de forma relacional e não são tratados separadamente, como por exemplo: o lugar é a segurança e o espaço é liberdade, estamos ligados ao primeiro e desejamos o segundo. (TUAN, 1980, p.3).

Para o autor, o lugar refere-se ao espaço dotado de valor simbólico, emocional, sentimental e de memória. Portanto, o espaço só passa a ser lugar quando adquire estas características. 0 espaço torna-se lugar a partir das experiências vividas em determinados locais. Assim, o que apenas é uma localização na cidade transforma-se em um lugar quando passa a ter definição e significado.

Os lugares podem ser definidos a partir do tipo de experiência que vivemos neles. Dessa forma, encontramos ao longo da obra de Tuan (1983), os lugares íntimos, os quais são definidos por lugares onde encontramos carinho, onde nossas necessidades fundamentais são consideradas e merecem atenção (TUAN, 1983, p.152).

Os lugares, além de se tornarem íntimos a partir da experiência vivida, podem ser visíveis ou invisíveis. Tuan explica a visibilidade de certos lugares a partir dos objetos estáveis que nos chamam a atenção e por eles atribuímos significados (TUAN, 1983, p.179). Os objetos que chamam a atenção vão variar de pessoa para pessoa, sua percepção pode ser influenciada pela cultura e variam de escalas.

A visibilidade dos lugares se dará através das experiências íntimas que teremos neles. Assim, para autor, a relação que temos com a rua em que moramos é completamente diferente da relação que temos com o bairro e com a cidade. Os sentimentos que temos com a rua em que moramos não estão relacionados diretamente com sentimentos que temos com o bairro. A visibilidade do bairro pode ser revelada, para Tuan, através:

[...] de um esforço da mente. Então, o bairro inteiro torna-se um lugar. Todavia, é um lugar conceitual e não envolve as emoções. Elas começam a dar cor ao bairro inteiro - recorrendo e extrapolando da experiência direta de cada uma de suas partes - quando se percebe que o bairro tem rivais e que está ameaçado de alguma maneira, real ou imaginária (TUAN, 1983, p.189)

0 relacionamento que estabelecemos com diferentes lugares acontece em escalas diferentes, tais como: com a nossa casa, com a rua em que moramos, com o bairro, com a cidade, com o país e com o mundo.

Além de Tuan, os estudos de Alicia Lindón destacam-se pela importância da compreensão do cotidiano através da dimensão do espaço enquanto do lugar. Em Lindón (2007) encontramos importantes reflexões sobre o estudo do espaço, que pode ser realizado através de diferentes aspectos, tais como:

El espacio visto a la luz del sujeto como habitante (Dardel, 1990). El lugar en la dialéctica entre el espacio y la sociedad. Esto significa que el lugar es concebido como productor de lo social y al mismo tiempo como producto social. Así, el lugar resulta de un movimiento constante entre fuerzas constituyentes y constituidas: los sujetos construyen el lugar y el lugar es construido socialmente, el lugar modela la vida social que allí se aloja. El lugar en la dialéctica entre las formas espaciales y los sentidos del lugar. Esto implica que el lugar se despliega en lo material y en lo no material. Así, lo material resulta de las formas de sentir, percibir y concebir los elementos materiales del entorno de algunos sujetos sociales (LINDÓN, 2007, p.9)

Para a autora, o lugar é entendido como uma construção social dotada de valor, de identidade, de significados, os quais estão em constante movimento de transformação dentro de uma perspectiva humanística. 0 lugar transforma-se na medida em que mudanças são provocadas, vivenciadas e praticadas pelos sujeitos que nele habitam.

Para Lindón (2012), os lugares são apreendidos através da narração dos sujeitos. Através da narração podemos conhecer os lugares, os valores atribuídos, os significados, as práticas socioespaciais e as experiências dos sujeitos em determinados lugares.

Ao analisarmos as propostas teóricas de Tuan (1983) e de Lindón (2012), é possível identificar que ambas se complementam, já que através da linguagem podemos expressar e decodificar as experiências que vivenciamos em determinados lugares.

Para a autora, a reconstrução das experiências vividas se dá através das narrativas. As pessoas desvelam o espaço e a espacialidade de diferentes formas. 0 narrador se vale do espaço para a simples localização dos fatos, para a atribuição de lembranças carregadas de significados, para a afirmação de si mesmo quando esse lugar está relacionado com prestigio ou para depreciação de si mesmo, quando esse lugar é perigoso. (LINDÓN, 2012)

Para a autora, os sujeitos não constroem lugares somente quando levantam edifícios, abrem caminhos ou cultivam a terra. Eles também constroem lugares ao falar deles e, fazendo isso, enfatizam algo, privilegiam acontecimentos e esquecem outros (LINDÓN, 2012, p18).

A partir das narrativas, podemos entrar em contato com a complexa rede de fios que se entrelaçam para a constituição do tecido que chamamos de lugar. Dito de outra forma, as narrativas permitem que as tra- 
mas de significados ganhem vida, tendo em vista que, através do ato de falar, da linguagem, podemos entrar em contato com as práticas socioespaciais dos sujeitos, evidenciando a indissociabilidade entre a fala e o fazer.

A narrativa, para Lindón (2012), é uma importante ferramenta para a apreensão dos lugares, contudo, a autora nos alerta sobre os limites do seu uso para o desvelamento da realidade. Entre esses limites encontramos: a reconstrução do vivido pelo sujeito nunca é completa; a aplicação da narrativa nas ciências sociais deve vir com a utilização do cruzamento de outras fontes de informação para uma aproximação mais fidedigna da realidade; e a experiência espacial não é comunicada da mesma forma que foi vivida, pois sempre será uma interpretação dessa experiência.

Os aportes teóricos acima foram importantes para a compreensão da construção de lugares de luta por equipamentos urbanos através da participação política no OP das lideranças comunitárias da Restinga.

É importante destacar que OP projetou a capital gaúcha no cenário político mundial, principalmente na década de 1990, e provocou uma grande mobilização nas discussões sobre democracia participativa no âmbito acadêmico. Contudo, a produção científica sobre o OP de Porto Alegre (FEDOZZI, 2001; AVRITZER, 2003; GUGLIANO, 2003; SOUZA, 2000; 2002; 2004 e 2006) está centrada principalmente nas inovações, mudanças e reflexos que esse instrumento provocou na democracia representativa brasileira.

Portanto, cabe salientar que ainda existem inúmeras lacunas a serem pesquisadas sobre o OP, pois as análises realizadas até o momento estão centradas na escala municipal, o que acaba generalizando os processos de participação política nos quais estão envolvidos os sujeitos moradores de cada região orçamentária. As seções que seguem deste artigo buscam evidenciar o entrelaçamento da participação política das lideranças comunitárias da Restinga e a construção de lugares do bairro que são visíveis ou parcialmente visíveis apenas para aqueles envolvidos no processo de reivindicação de melhorias para o bairro.

0 artigo está divido da seguinte forma: primeira parte - breve história do OP; segunda parte - pequena história do bairro Restinga e as conquistas do OP no bairro; terceira parte - os lugares invisíveis do bairro e considerações finais.

\section{Orçamento Participativo de Porto Alegre}

Desde sua implementação, o OP de Porto Alegre, o qual já completou 25 anos, transformou-se em uma referência mundialmente reconhecida pela participação da população na discussão e deliberação do orçamento público nas prioridades das regiões mais carentes da cidade.

O OP, conforme Avritzer (2003), é definido como um mecanismo que visa à articulação entre a democracia representativa e a democracia participativa, sendo caracterizado por quatro elementos: a) a abertura da soberania da democracia representativa para a democracia participativa através de um conjunto de assembleias regionais e temáticas que se utilizam de critérios e nas quais todos os cidadãos podem participar, com igual poder de deliberação; b) o OP introduz no cenário da democracia representativa elementos de participação local, tais como a assembleia regional, e elementos de delegação, tais como os conselhos na escala municipal, combinando métodos da tradição de democracia participativa; c) o OP fundamenta-se no princípio de autorregulamentação, pois as regras são definidas pelos seus participantes e podem sofrer alterações periódicas; d) o OP é uma tentativa de reversão de prioridades na distribuição de recursos do orçamento público em escala municipal através de uma fórmula técnica que varia de cidade para cidade, tendo como objetivo a identificação de prioridades orçamentárias que privilegiam os setores mais carentes da população.

Cabe salientar ainda que o OP também projetou a cidade de Porto Alegre internacionalmente, pois através de sua implantação a cidade tornou-se a capital da democracia participativa e passou a ser sede do Fórum Social Mundial.

A organização do OP atual, segundo o Regimento Interno do OP - Critérios Gerais, Técnicos e Regionais de 2010/2011, se dá em dezessete regiões da cidade (Figura 01), tendo um ciclo anual divido em: reuniões preparatórias, assembleias regionais, assembleias temáticas, análise das demandas e matriz orçamentária, votação da matriz orçamentária, detalhamento do plano de investimentos e serviços, discussões nos fóruns temáticos e regionais do regimento interno e votação do regimento interno.

É importante salientar que as regras que regem o OP podem ser alteradas a qualquer momento, visto que o Regimento Interno é discutido em todos os ciclos do OP e pode ser modificado ou melhorado pelos participantes do processo.

\section{Restinga - Oitava Região do Orçamento Partici- pativo}

A Restinga localiza-se a $22 \mathrm{~km}$ do centro da cidade de Porto Alegre. Os estudos sobre o bairro realizados por Soster (2001), Dal Molin (2007) e Gamalho (2009) apontam que sua formação iniciou-se a partir da aquisição pela Prefeitura de Porto Alegre, em 1960, de uma área para remoção da população moradora das malocas na zona central de Porto Alegre.

As remoções da população do centro da cidade para a Restinga são fruto da política empregada pela Prefeitura, a qual tinha como slogan "Remover para Promover", sendo seu principal objetivo o desenvolvimento de Porto Alegre, a limpeza do que era feio e sua realocação para bem longe do centro da cidade.

As populações removidas foram jogadas no es- 


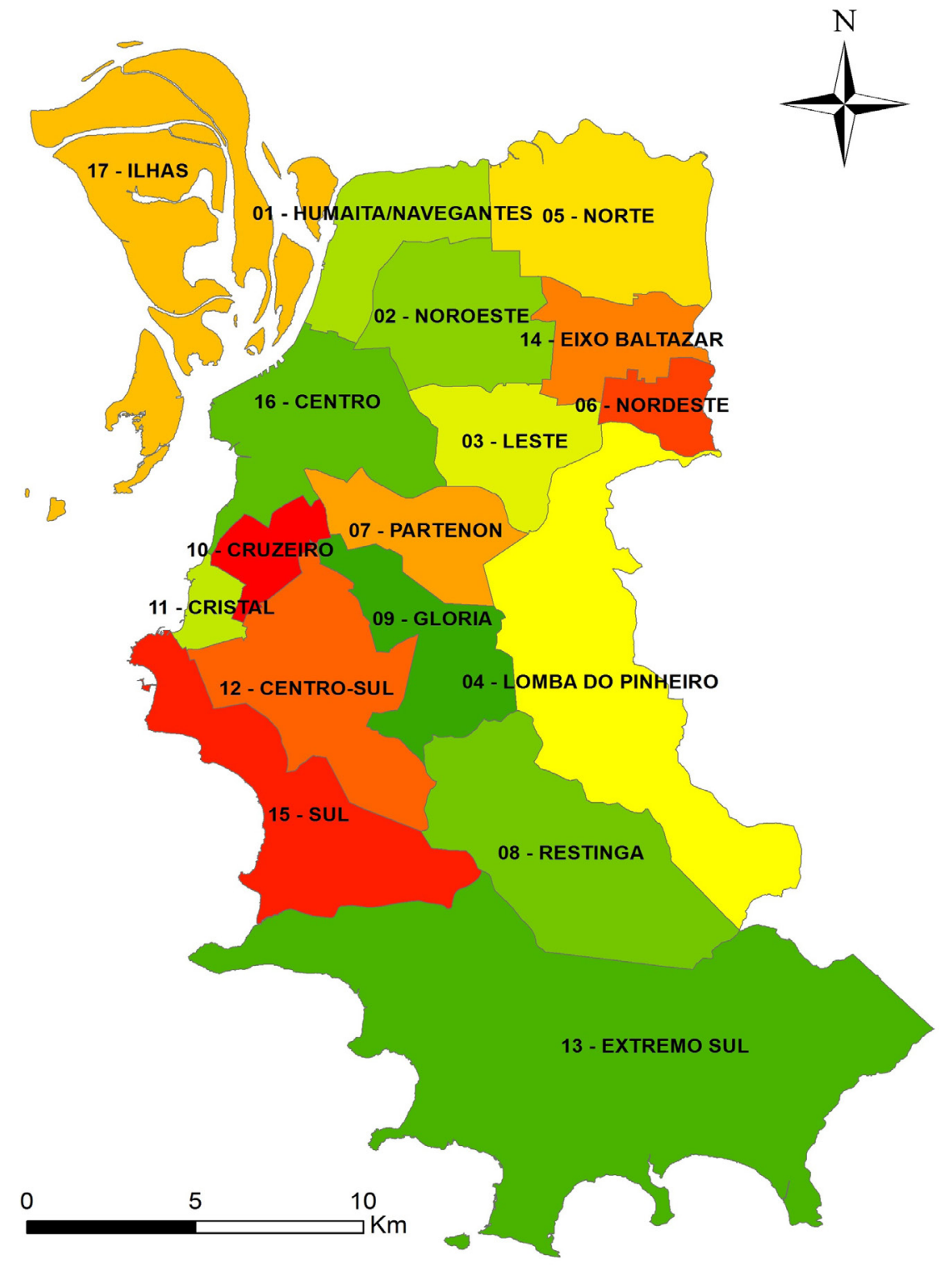

Fonte: Prefeitura de Porto Alegre

paço que, posteriormente será chamado de Restinga, onde não existe nenhum equipamento público, sem água, esgoto, luz, escolas, postos de saúde, entre outros. A falta total de infraestrutura fez com que os moradores se organizam para reivindicar junto ao poder públicos melhores condições de sobrevivência.

No último censo realizado pelo Instituto Brasileiro de Geografia Estatística (IBGE), o bairro possui atualmente 60.729 habitantes, representando $4,31 \%$ da população do município de Porto Alegre, tendo uma área de $38,56 \mathrm{~km}^{2}$.

Para reivindicar melhores condições de vida para a população residente naquele espaço, os moradores começaram a se organizar em associações de moradores, organizações não governamentais e outras formas de organizações populares. Essas organizações conquistaram inúmeras melhorias para bairro.

Dessa forma, as entrevistas realizadas apontam que a implementação do OP em Porto Alegre foi importante para o bairro, pois se tornou o principal instru- mento de conquista de equipamentos urbanos.

Para nossos narradores, nos últimos anos o OP tornou-se a principal via de conquista de equipamentos urbanos na Restinga. Conforme as falas das lideranças: ...eu tenho outros mecanismos para conseguir coisas para comunidade, o OP não é um mecanismo só, o OP é uma porta, é uma das portas principal... (Vitor, fev.2012). Naquela época o OP era o ponto de encontro não para discutir, mas também para mobilizar, tinha que ir lá para dar conta... (Paula, fev.2012).

Um dos fatores que contribuiu para que o OP pudesse se tornar a principal via de conquista de equipamentos urbanos na Restinga foi a crença das pessoas na iniciativa, além da entrega das demandas. Segundo as lideranças: ...naquele tempo a participação popular era muito grande. E as pessoas acreditavam no OP; podia demorar, mas nos tínhamos esperança de sair. (Fabíola, fev.2011).

As primeiras demandas do OP na Restin ga estavam centradas, principalmente, no asfaltamento de 
ruas, iluminação pública, saneamento e moradia, tal como nossos entrevistados descrevem a seguir:

... O que acontece com o orçamento, a comunidade decide o que é prioridade, vamos priorizar: construir uma escola, vamos priorizar, quando o Olívio veio a ser prefeito de Porto Alegre muita gente demandava asfalto porque nas vilas não tinha infraestrutura e ninguém se dava conta. Pode ser que isso virou politicagem, mas o Olívio entrou nas vilas de POA e viu o que realmente as vilas não tinham asfalto, não tinham luz, não tinham esgoto (Carla, jan.2011).

As narrativas das lideranças comunitárias foram complementadas pelos dados obtidos através de levantamento no website da Prefeitura de Porto Alegre, seção Acompanhamento de obras OP. Através dos dados do website, é possível confirmar que as principais demandas foram por pavimentação e saneamento.

Além disso, foram obtidos através do OP outros equipamentos urbanos, tais como: saneamento básico, iluminação pública, construção de creches, reforma de escolas de ensino fundamental, reforma e construção de postos de saúde, entre outros.

Os narradores destacam a importância da conquista desses equipamentos públicos para ter a garantia de outros equipamentos e serviços públicos, tais como: atendimento médico de emergência realizado por ambulâncias e transporte público. Além disso, a iluminação pública está relacionada a outros fatores, tais como: a diminuição da criminalidade e dos perigos eventuais que podem acometer os moradores da Restinga. As lideranças dizem claramente que a iluminação pública conquistada pelo OP diminui a atuação de criminosos e do tráfico em determinados locais da Restinga.

...dinheiro era pouco, então muitas vezes
numa rua ele (Olívio) colocava três pos-
tes com luz. Uma esquina, um no meio
e outra na esquina. Aquilo já dava uma
baita visibilidade e diminuía bastante a
questão da criminalidade, que ninguém
se liga, aonde entra o governo, entra in-
fraestrutura e a criminalidade diminui,
então muita gente demandava asfalto...
(Carla, jan.2011).

A conquista dos equipamentos urbanos via participação política no OP permitiu a construção de lugares no bairro que são visíveis apenas para as lideranças que fizeram parte do processo de reivindicação e de luta por melhores condições de vida. Dessa forma, a compreensão da construção desses lugares é o foco da próxima seção deste artigo.

\section{Os lugares invisíveis ou parcialmente visíveis do bairro Restinga}

A análise das narrativas através do holograma espacial evidenciou a construção social dos lugares visíveis ou parcialmente visíveis da Restinga a partir da participação das lideranças comunitárias do bairro Restinga no OP.

Os hologramas socioespaciais não são simples descrições das experiências espaciais dos sujeitos em determinados locais da cidade, pois buscam compreender e apreender esses lugares em todas as suas dimensões.

O holograma, para Lindón (2007b), também permite ao pesquisador captar lugares invisíveis ou parcialmente visíveis dentro da cidade, os quais muitas vezes são visíveis apenas para determinados grupos que compartilham experiências íntimas.

Para a construção do holograma, foram realizadas narrativas de vida espaciais, as quais, para Lindón (2012), são importantes ferramentas para a reconstrução das experiências vividas pelos sujeitos, pois ao narrarmos conectamos lugares, atribuímos significados e acessamos os conhecimentos construídos ao longo de nossas vidas. Conforme a autora, "El sujeito conecta, asocia y contrasta su espacio de vida presente con otros espacios vividos" (LINDÓN, p. 21, 2012).

Essa visibilidade ou invisibilidade é determinada pelas experiências que vivenciamos no local. Assim, mesmo vivendo no mesmo bairro, a visibilidade daquele lugar será diferente para os grupos de pessoas que residem naquele local. 0 lugar visível para nossos narradores dos primeiros tempos na Restinga carrega, na sua grande maioria, características negativas e faz com que não tivessem nenhum prazer em morar ali, mesmo tendo conquistado suas casas próprias.

No entanto, como o lugar é o espaço inacabado e está sempre em movimento, a precariedade, que poderia ter se transformado em motivo para uma vida cheia de reclamações, transformou-se na principal motivação para a participação política, organização e luta por equipamentos públicos na Restinga.

A participação política é entendida aqui a partir de Avelar (2004), que define participar como sendo: tomar parte em algo que se refere à política. Para a autora, a participação política se dá através das formas mais simples, tais como: conversas em locais públicos sobre política, até as mais complexas como, por exemplo, o envolvimento na mobilização de grandes grupos para protestar contra a fome no mundo, a violência nas grandes cidades e ainda o engajamento em partidos políticos, o ato de votar e de fazer parte do governo.

As lideranças destacam que a Restinga é outra após a implementação do OP de Porto Alegre, pois os locais foram se transformando em lugares através das conquistas de equipamentos públicos: ... a gente conseguiu ônibus, consegui posto de saúde, creche, tem uma melhor...(Fabíola, fev.2012). 
A materialização dos equipamentos urbanos conquistados vai além das suas construções e do bom funcionamento do bairro, pois esses equipamentos são símbolos das lutas, das brigas, dos desejos de um bairro melhor e da conquista dos direitos e da cidadania através da participação no OP. Nossas narrativas apontam que a principal motivação para a participação política dos moradores foi a precariedade ou ausência de equipamentos públicos.

A conquista desses equipamentos transformou o bairro, pois muitas ausências foram preenchidas através da luta dos moradores. As lideranças destacam que não conquistaram nada sozinhos e que a comunidade teve papel fundamental nestas lutas, como podemos observar:

... Na época eu ia de carro, ônibus não consegui, fazer tudo, despesa da gente e voltando aqui a nossa comunidade, assim o que me deixa, eu digo que me engrandece, porque foi trabalho, eu digo não é só eu, porque tinha mais gente, uma diretoria e toda a comunidade apoiando... (Carlos, fev.2012)

A participação no OP fez com que nossos narradores, juntamente com a comunidade, conquistassem pavimentação para as ruas, redes de esgoto, iluminação pública, novas escolas de ensino fundamental e infantil, ampliação das escolas já existentes, entre outros equipamentos urbanos.

O lugar passou a ser marcado por equipamentos que foram conquistados com o envolvimento dos moradores da Restinga, ao contrário do que Tuan (1980) aponta, no sentido de que a participação das pessoas na construção das obras na contemporaneidade fica restrita apenas à colocação da pedra fundamental.

No OP acontece o contrário do que é afirmado por Tuan (1980), pois através da participação política as pessoas apontam as obras importantes para cada região, acompanham sua construção e ainda fiscalizam seu andamento. Nesse sentido, de acordo com nossos narradores:

...Eu dava explicação de como estava a
situação do processo de regularização,
da situação das obras, se ela foi aprova-
da ou não, eu sabia passo de cada obra,
qualquer morador que me perguntava
sobre passos da comunidade, eu não dei-
xava sem resposta, eu tinha resposta na
hora para dar...(Carlos, fev.2012).

Tendo em vista as concepções acima relacionadas às obras do $\mathrm{OP}$, além dos preceitos de Tuan, é possível afirmar que, no caso da Restinga, os equipamentos pú- blicos são a materialização da organização do bairro. Dessa maneira, se constituem como símbolos, materializando no lugar o entrelaçamento entre a participação política no OP e a vida daquelas pessoas que lutaram por eles.

A análise das narrativas através do holograma espacial também possibilitou tornar visível o lugar das conquistas alcançadas a partir da organização dos moradores do bairro, as quais são mais visíveis para o grupo de lideranças comunitárias que participaram diretamente desse processo, mas que podem ser menos visíveis ou invisíveis para os outros moradores.

Os lugares da Restinga que se tornaram visíveis foram aqueles resultantes das lutas das lideranças comunitárias e da população que reside no bairro por equipamentos públicos. São lugares repletos de significados, pois entrelaçam participação política, histórias de vida e transformações socioespaciais.

A materialização desses lugares é visualizada na paisagem do bairro, pois as ruas que não possuíam asfalto ou iluminação pública hoje se encontram pavimentadas e iluminadas. Onde não havia escola ou faltavam vagas para as crianças, hoje a escola foi construída ou ampliada, e onde as pessoas sofriam com a falta de saneamento básico hoje esta necessidade já foi atendida.

0 lugar-Restinga ${ }^{1}$ visível para as lideranças comunitárias está relacionado à mobilização dos seus moradores através da participação política no OP e em outras organizações. Esses outros significados estão intimamente associados a esses lugares de luta, de persistência, de organização e de mobilização, afinal a Restinga deixa de ser "o nada" para essas lideranças e passa a fazer parte de suas vidas e de suas trajetórias de participação.

\section{Considerações Finais}

As narrativas produzidas pelas lideranças comunitárias revelaram os lugares do bairro que, para outros moradores, estavam invisíveis ou parcialmente visíveis. O lugar aqui é entendido a partir da perspectiva de Tuan (1983), ou seja, o lugar é a dimensão do espaço ao qual atribuímos significados, características, símbolos, além de possuir memória.

Os lugares da Restinga que se tornaram visíveis foram aqueles resultantes das lutas dessas lideranças comunitárias e da população que reside no bairro por infraestrutura. São lugares repletos de significados, pois entrelaçam participação política, histórias de vida e transformações socioespaciais.

A materialização desses lugares é visualizada na paisagem do bairro, pois as ruas que não possuíam asfalto ou iluminação pública hoje se encontram pavimentadas e iluminadas. Onde não havia escola ou faltavam vagas para as crianças, hoje a escola foi construída

${ }^{1}$ Lugar-Restinga - ora designa-se bairro Restinga como divisão administrativa da cidade e ora se faz referencia ao lugar relacionado à topofilia ou topofobia expressa pelos moradores. 
ou ampliada, e onde as pessoas sofriam com falta de saneamento básico hoje esta necessidade já foi atendida.

A participação política no OP possibilitou às lideranças a construção de lugares que não existiam no bairro, pois cada equipamento urbano reivindicado pela população e entregue pela prefeitura torna-se símbolo da mobilização popular e da organização dos moradores. Entretanto, por diferentes razões, esses equipamentos podem ser vistos pelo restante da população como apenas mais um equipamento urbano.

Por fim, cabe salientar que para as lideranças, os equipamentos urbanos conquistados carregam suas histórias, suas lutas e suas memórias. Para encerrar este artigo, citamos um trecho da narrativa de Carlos, o qual afirmou que cada pedacinho do asfalto conquistado é uma parte dele que está sobre a rua. Essa narrativa nos permite afirmar que os lugares de luta na Restinga se constituíram e ainda se constituem através da organização dos seus moradores e da pressão popular junto ao poder público.

... O que acontece com o orçamento, a comunidade decide o que é prioridade, vamos priorizar: construir uma escola, vamos priorizar, quando o Olívio veio a ser prefeito de Porto Alegre muita gente demandava asfalto porque nas vilas não tinha infraestrutura e ninguém se dava conta. Pode ser que isso virou politicagem, mas o Olívio entrou nas vilas de POA e viu o que realmente as vilas não tinham asfalto, não tinham luz, não tinham esgoto (Carla, jan.2011).

As narrativas das lideranças comunitárias foram complementadas pelos dados obtidos através de levantamento no website da Prefeitura de Porto Alegre, seção Acompanhamento de obras OP. Através dos dados do website, é possível confirmar que as principais demandas foram por pavimentação e saneamento.

Além disso, foram obtidos através do OP outros equipamentos urbanos, tais como: saneamento básico, iluminação pública, construção de creches, reforma de escolas de ensino fundamental, reforma e construção de postos de saúde, entre outros.

Os narradores destacam a importância da conquista desses equipamentos públicos para ter a garantia de outros equipamentos e serviços públicos, tais como: atendimento médico de emergência realizado por ambulâncias e transporte público. Além disso, a iluminação pública está relacionada a outros fatores, tais como: a diminuição da criminalidade e dos perigos eventuais que podem acometer os moradores da Restinga. As lideranças dizem claramente que a iluminação pública conquistada pelo OP diminui a atuação de criminosos e do tráfico em determinados locais da Restinga. ...dinheiro era pouco, então muitas vezes numa rua ele (Olívio) colocava três postes com luz. Uma esquina, um no meio e outra na esquina. Aquilo já dava uma baita visibilidade e diminuía bastante a questão da criminalidade, que ninguém se liga, aonde entra o governo, entra infraestrutura e a criminalidade diminui, então muita gente demandava asfalto... (Carla, jan.2011).

A conquista dos equipamentos urbanos via participação política no OP permitiu a construção de lugares no bairro que são visíveis apenas para as lideranças que fizeram parte do processo de reivindicação e de luta por melhores condições de vida. Dessa forma, a compreensão da construção desses lugares é o foco da próxima seção deste artigo.

\section{Referências}

AVRITZER, Leonardo Zander (Org). A inovação democrática no Brasil. São Paulo: Cortez, 2002.

AVELAR, Lúcia. Sistema Político Brasileiro: Uma Introdução. Rio de Janeiro: Fundação Konradadenauer-stiftung, 2004. p. 223-235. Disponível em: <http://www. saudebucalcoletiva.unb.br/ensino/introducao_a_ciencia_politica/25_Lucia_Avelar_Participacao_Politica.pdf $>$. Acesso em: 07 mar. 2012.

BONETTO, Helena. As Percepções topofílicas/topofóbicas das lideranças comunitárias do bairro Restinga antes e depois da implementação do orçamento participativo. Dissertação (Mestrado em Geografia). Programa de Pós-Graduação em Geografia da Universidade Federal do Rio Grande do Sul, Porto Alegre, 2013.

DAL MOLIN, Fábio. Redes sociais e micropolíticas da juventude. Tese (Doutorado em Sociologia) - Universidade Federal do Rio Grande do Sul, Porto Alegre, 2007.

GAMALHO, Nola Patrícia. A Produção da periferia: das representações do espaço ao espaço de representação no Bairro Restinga. Dissertação (Mestrado em Geografia) Universidade Federal do Rio Grande do Sul, Porto Alegre, 2009.

LINDÓN, Alicia. El Imaginário Suburbano: Topofilias y Topofobias. Cidades: Revista científica/Grupo de Estudos Urbanos, v. 2, n.4, 2005, p 289-313. 
. Los imaginarios urbanos y el constructivismo geográfico: los hologramas espaciais. Revista Eure, Santiago de Chile, v XXXIII, n. 99, p.31-46, ago. 2007a. Disponível em: <http://www.scielo.cl/pdf/eure/v33n99/art04. pdf>. Acesso em: 12 jul. 2012.

El constructivismo geográfico y las aproximaciones cualitativas. Revista de Geografía Norte Grande, Santiago de Chile, n. 37, p.5-21, jun. 2007b. Disponível em: <http://www.scielo.cl/scielo. php?pid=S0718-34022007000100001\&script=sci_arttext>. Acesso em: 12 jul. 2012.

La ciudad y la vida urbana a través de los imaginarios urbanos. Revista Eure, Santiago de Chile, v. XXXIII, n. 99, p.7-16, ago. 2007c. Disponível em: <http://www. scielo.cl/pdf/eure/v33n99/art02.pdf>. Acesso em: 03 maio 2012.

Las narrativas de vida espaciales: uma expresión del pensamiento geográfico humanista y constructivista. Texto enviado através de correspondência eletrônica, ainda não publicado pela autora.
HOLZER, Werther. O Lugar na Geografia Humanística. Revista Território. Rio de Janeiro. ano IV, n. 7.p. 67-78. jul./ dez. 1999. Disponível em: <http://www.revistaterritorio. com.br/pdf/07_6_holzer.pdf.>. Acesso mar. 2012.

PORTO ALEGRE (Prefeitura Municipal). Regimento Critérios gerais, técnicos e regionais - 2011/2012. Porto Alegre, 2010. Disponível em: <http://lproweb.procempa.com.br/pmpa/prefpoa/op/usu_doc/pa002010-op_reg_int.pdf> Acesso em: 15 de mar. de 2011.

SOSTER, Ana Regina de Moraes. Porto Alegre: A cidade se reconfigura com as transformações dos bairros. Dissertação (Mestrado em História). Programa de Pós-Graduação em Historia, Pontifícia Universidade Católica do Rio Grande do Sul. Porto Alegre, 2001.

TUAN, Yi-Fu. Espaço e lugar: a perspectiva da experiência. São Paulo: Difel, 1983.

\title{
INVISIBLE PLACES IN RESTINGA NEIGHBORHOOD: THE PARTICIPATION OF COM- MUNITARIAN LEADERSHIPS IN PARTICIPATORY BUDGET IN PORTO ALEGRE
}

\begin{abstract}
Resumo: Abstract: This article results from the research performed as a part of a master's thesis-Topophilic/topophobic perceptions of communitarian leaderships from the Restinga neighborhood before and after the implementation of Participatory Budgeting. The main objective is evidencing and understanding how the political participation and the acquisition of public equipment through Participatory Budgeting (PB) have contributed for the construction of battlefields for urban equipment, which are visible only to communitarian leaderships in the Restinga neighborhood. The theoretical approach of this investigation is found in the works of Yi-Fu Tuan and Alicia Lindón. The concepts used are those of space, place, invisible places and partially visible places. The methodological procedures used to understand the places in the neighborhood before and after the implementation of PB were literature review, narrative interviews, survey of construction works in the website of Porto Alegre City Hall and the construction of databanks for the composition of thematic and graphic maps. For data analysis of the transformation of the places, the spatial hologram was used, which is a qualitative research technique developed by Lindón to allow the understanding of senses, of the web of meanings and symbolisms attributed to places through the spatial experiences of the subjects. Narrative analysis has shown that the places in the Restinga neighborhood that have become visible were those resulting from struggles for urban equipment by communitarian leaderships and the population that lives in the neighborhood. These are places filled with meanings, since they interweave political participation, life stories, and socio-spatial transformations.
\end{abstract}

Keywords: Participatory budgeting, place, political participation, Restinga. 